\title{
القتل بدافع الشرف- دراسة تحليلية مقارنة بين التشريع المصري والفلسطيني
}

\author{
أيمن نصر عبدالعال
}

أستاذ القانون الجنائي المساعد- عميد كلية القانون والممارسة القضائية

جامعة فلسطين- فلسطين

dr.aymannasr66@gmail.com

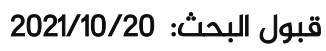

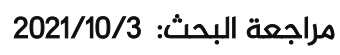

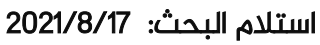


www.refaad.com
المجلة الدولية للدراسات القانونية والفقهية المقارنة

International Journal of Legal and Comparative Jurisprudence Studies (LCJS)

Journal Homepage: https://www.refaad.com/views/LCJS/Home.aspx

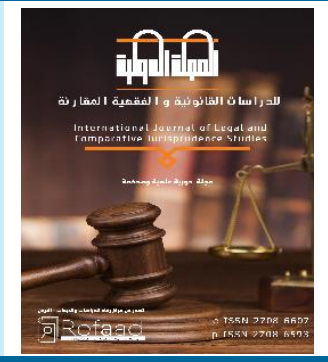

ISSN: 2708-6607(Online) 2708-6593(Print)

القتل بدافع الشرف- دراسة تحليلية مقارنة يين التشريع المصري والفلسطيني

\author{
أيمن نصر عبدالعال \\ أستاذ القانون الجنائي المساعد- عميد كلية القانون والممارسة القضائية- جامعة فلسطين- فلسطين \\ dr.aymannasr66@gmail.com
}

DOI: https://doi.org/10.31559/LCJS2021.2.3.1 2021/8/17 مراجتلام البحثة البحث: 2021/10/3 قبول البحث: 2021/10/20

الملتخص:

الحياة نعمة كبرى وهبها الله تعالى للإنسـان وفرض حمايتها بما رسخته الشرائع السماوية لحماية النفس الإنسانية من أي اعتداء، وهو

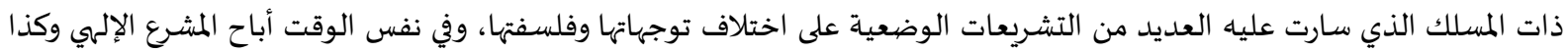

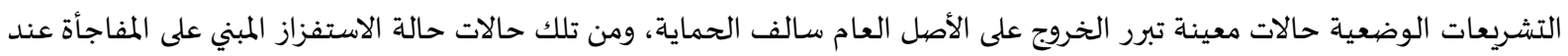

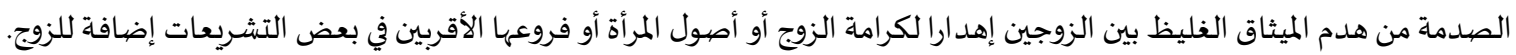

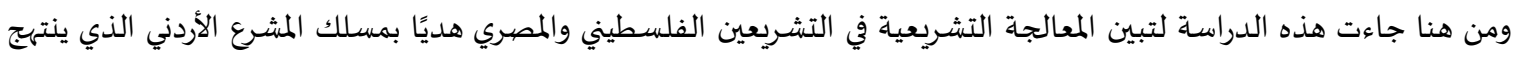

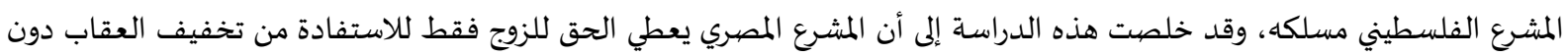

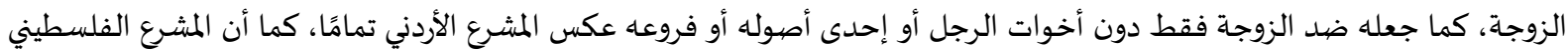
ألغى هذا العذر قانونًا وقضياء.

الكلمات المفتاحية: القتل؛ دافح الشرف؛ عمد؛ عذر مخفف؛ جريمة الزنا.

المقدمة:

الشرف قيمة معنوية تكاد تكون أهم ما يملكه الإنسان كقيمة معنوية، ويحمل هذا المصطلح دلالات عديدة خاصة في المجتمعات العربية ومن

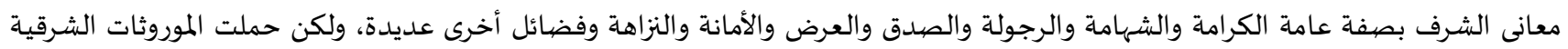

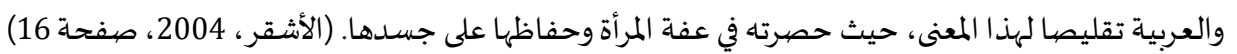

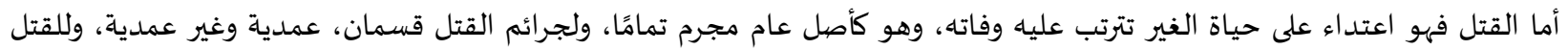

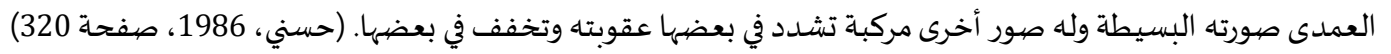

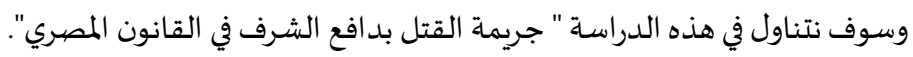
أهمية الدراسـة:

تكمن أهمية هذه الدراسة فيما يلي: بيان أهمية الحياة بالنسبة لكل إنسان، وإظهار ما يمثله الاعتداء على الحياة من خطر يهدد كيان المجتمع.

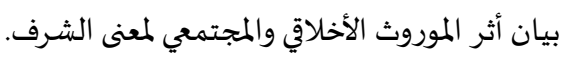

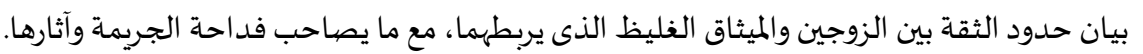
بيان آثار الجريمة على الجاني وباقي أسرته وذوى المجنى عليها أو عليهما. بيان النموذج القانوني لجريمة القتل وأثر الظرف الجديد الذى يحيط بها. 
إشكالية الدراسـة: تكمن إشكالية الدراسة في إجراء التوازن بين حماية الحق في الحياة وبين الاستفزاز الذي يُغيب الملكات والإدراك عند مشاهدة المرأة في وضع غير سوي ويتضيح ذلك في الأسئلة التالية:

هل ساوى المشرعان المصري والفلسطيني بين الرجل والمرأة فيما يتعلق بالشرف كدافع للقتل؟ ما هو نطاق الأشخاص المستفيدين من هذا العذر في كل من التشريعين؟ بـ هـئ

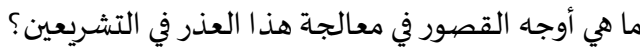
هل يعتبر الشرف سبباً للإباحة أم عذراً مخففًا؟ ماهي التعديلات التشريعية لهذا العذر وما أثرها؟

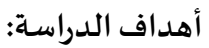
تهدف الدراسة إلى استعراض مسلك المشرعين المصري والفلسطيني في معالجة هذه الجريمة واستظهار مدى توافر الصورة المجردة للقتل ومدى أثر الظرف الجديد المصاحب لله على النموذج المجرد لجريمة القتل وبيان حدود النطاق الشخصي للاستفادة منه، والمعالجة التشريعية المتطورة لهذا

سوف يكون المنهج الوصفي التحليلي وكذا المنهج المقارن هو المنهج المتخذ مسلكا لهذه الدراسة من خلال بيان المعالجة التشريعية لتلك الجريمة

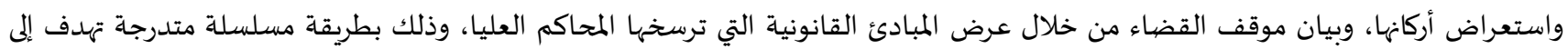
الوصول إلى كيفية وأسلوب المعالجة التشريعية المثلى لتلك الجريمة في التشريعين المصري والفلسطيني. تقسيم الدراسـة: سوف نقسم دراسة هذا الموضوع إلى مبحثين نتناول في الأول المعالجة القانونية للظروف المصاحبة للجريمة وآثارها. وفي الثاني القتل العمدي في صورته المخففة (قتل الزوج زوجته إذا فاجأها متلبسة بالزنا).

\section{المبحث الأول: المعالجة القانونية للظروف المصياحبة للجريمة و آثارها}

تتقاسم قانون العقوبات في التشريع المصري وغيره من التشريعات نظريتان الأولى هي النظرية العامة للجريمة، والثانية هي النظرية العامة للعقوبة

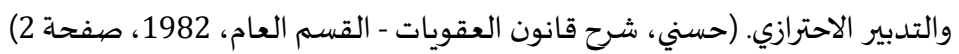
ومن المعلوم أن النظرية الأولى تشتمل على بيان الركن الشرعي للجريمة وكذا ركنها المادي وأيضًا الركن المعنوي لها بشكل عاديا لـام لكل الجرائم، أي بيان الأركان العامة للجريمة والأحكام التي توضع لها ووضع ضيوابط عامة للتفرقة بين المشروع وغير المشروع من الأفعال، فضلًا عن بيان القواعد العامة للعقوبات والتد ابير.

أما في القسم الخاص ففياء يتم تناول دراسة الجرائم بشكل محدد من حيث بيان الأركان الخاصة بكل جريمة على حدة والعقوبة المقررة لها.

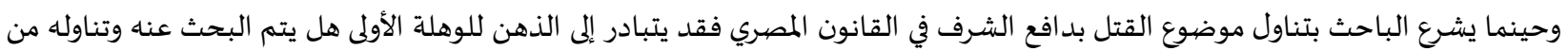
منظور عام، أم من منظور خاص؟

المطلب الأول: الظروف المغيرة لوصف الجريمة أومقدار العقوبة

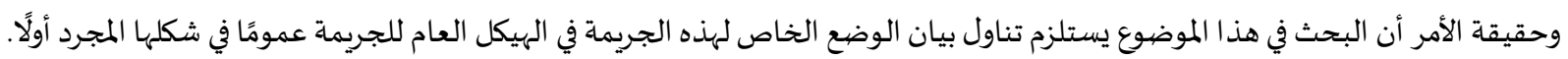

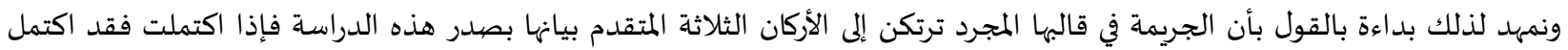

النموذج الإجرامي الذي عناه المشـرع للسلوك المادي الذى يشكل اعتداء على حق يحمياه القانون وقرر لله الشارع جزاء جنائيًا.

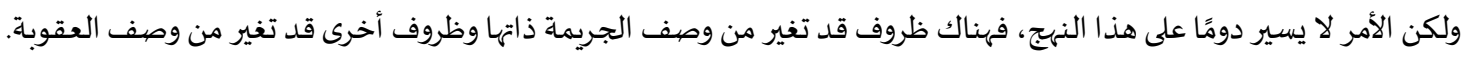
أما الظروف التي تغير من وصف الجريمة فهي عناصر تدخل في تكوينها كي تحدد وصفها القانوني بين مجموعة الجرائم التي تحمل اسمًا واحدًا،

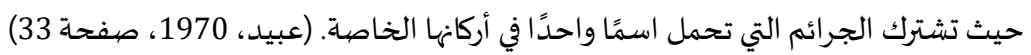

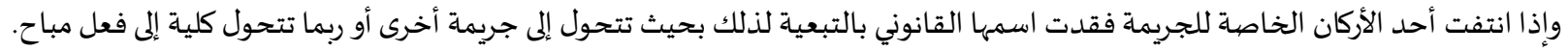

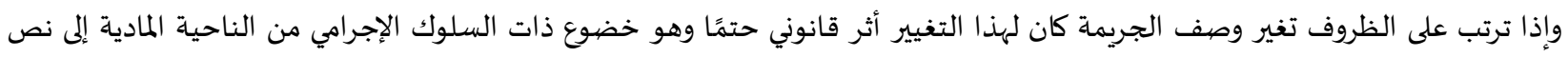
قانوني آخر مغاير لما كان سيخضع له ذات السئ السلوك في صورته المجردة من هذا الظرف. 


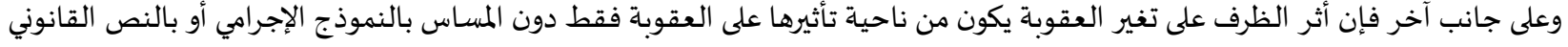

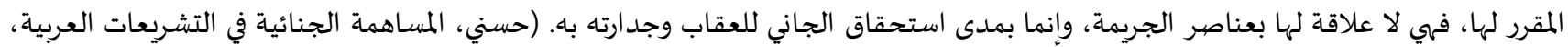

2004 ، صفحة 189

وتنقسم الظروف إلى قسائم متعددة بتنوع الأسس التي يقوم علهيا التقسيم وهي تتنوع إلى أساس يرتكن إلى مقدار العقوبة وآخر إلى مقدار اتساع نطاق العقوبة وثالث إلى طبيعتها.

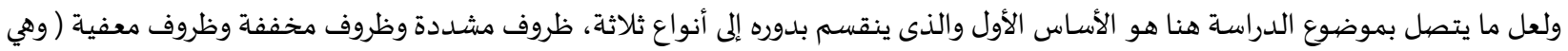

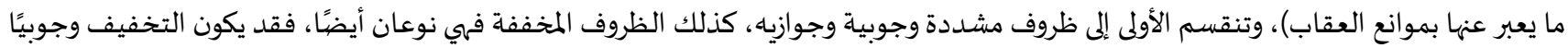

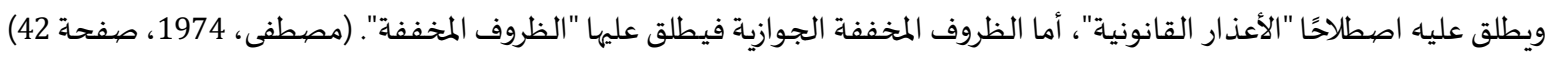

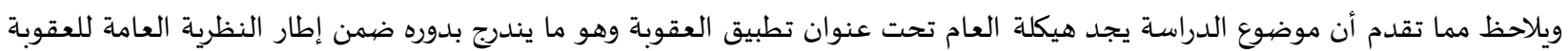
كأصل عام كما تقدم البيان.

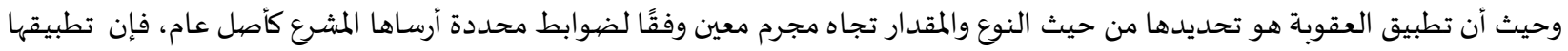

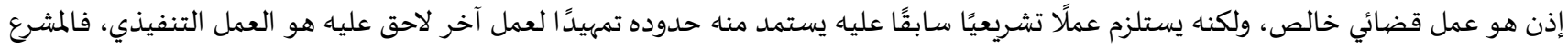

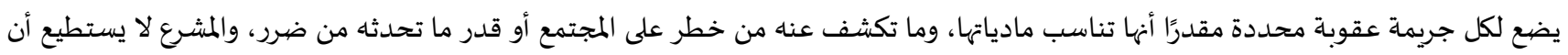

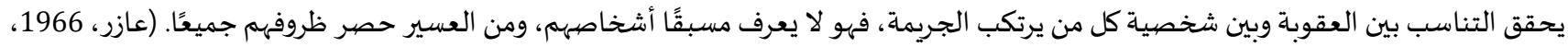

صفحة 23)

فالمشرع يضع العقوبة التي يرى ملاءمتها لشخص عادى في ظروف عادية ويرى أهها عادلة في ضوء هذا التحديد (وذلك بحسبان أن القاعدة

القانونية عامة ومجردة) .

ولكناه في الوقت ذاته يسلم بأنه قد يرتكب ذات الجريمة شخص ذو ظروف غير عادية فعندئذ تصبح العقوبة غير عادلة وغير ملائمة لهذا النموذج الإجرامي.

من هنا تبرز الوظيفة القضائية للعمل على استخراج التحديد الواقعي للعقوبة من التجريد الجامد لها.

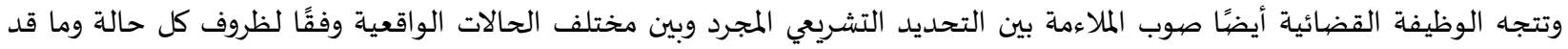

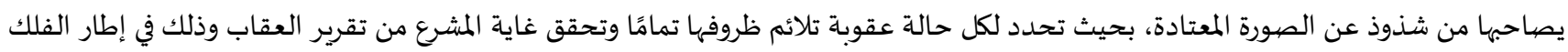

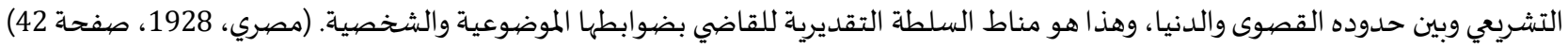

المطلب الثاني: صور القتل و أنواع الأعذار في التشريع الفلسطيني

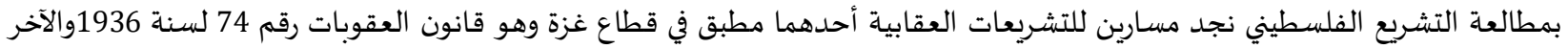

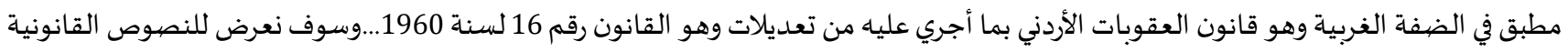
ذات الصلة بشيء من الإيضاح حيث تجرى نصوص المواد 212،213،215،213 من قانون العقوبات الفلسطيني 74 لسنة 1936 حيث أن (المادة 212

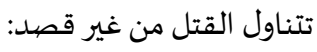
مع مراعاة أحكام المادة 214 من هذا القانون، كل من تسبب في موت شخص آخر، بفعل أو ترك غير مشروع يعتبر أنه ارتكب جناية وتعرف هذه الجناية بالقتل عن غير قصاعد.

وقد بيَّت المادة 213 العقوبات المقررة لهذه الصهورة حيث نصت على أن: كل من أدين بارتكاب جناية القتل عن غير قصهد، يعاقب بالحبس المؤبد. أما المادة 214 فقد تناولت القتل قصيدًا: حيث أوردت أن كل من:

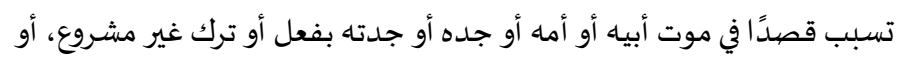

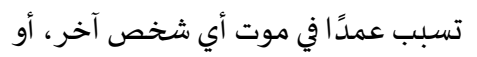

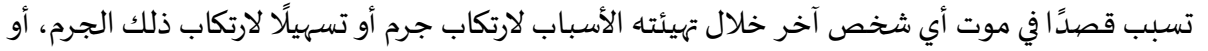

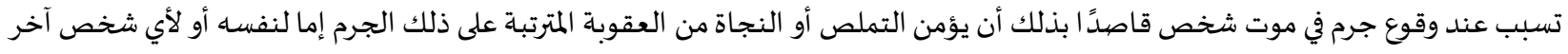

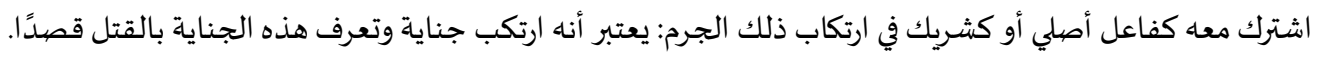

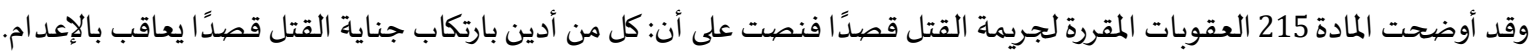

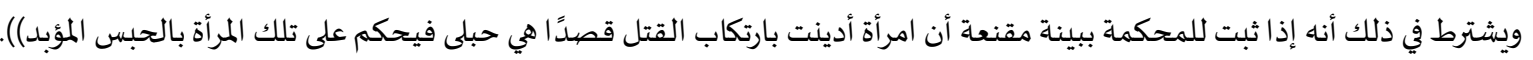
وبمطالعة تلك النصوص يتضح منها مسلك المشرع الفلسطيني في القانون رقم (74) لسنة 1936 لمعالجة القتل بظروفه المختلفة وتناول صوره 
بينما نصت المادة (18) على أنه في حالة الضرورة ((يجوز قبول المعذرة في ارتكاب فعل أو ترك يعتبر إتيانه جرمًا لولا وجود تلك المعذرة إذا كان في

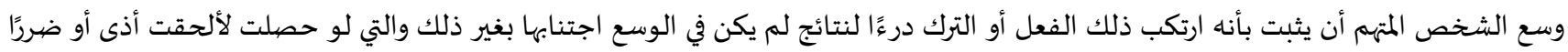

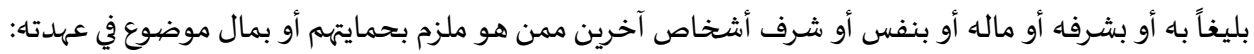

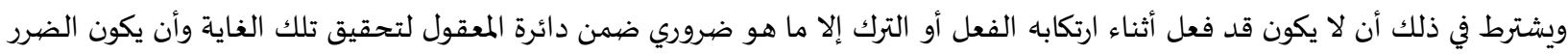
الناجم عن فعله أو تركاء متناسباً مع الضرر الذي تجنبـه) ).

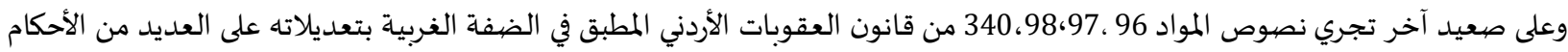

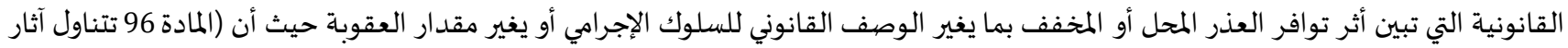

العذر المحل فقررت: إن العذر المحل يعفي المجرم من كل عقاب على أنه يجوز أن تنزل باه عند الاقتضاء تدابير الاحتراز كالكفالة الاحتياطية مثلاً.

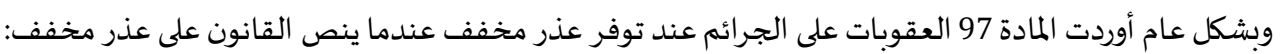
إذا كان الفعل جناية توجب الإعدام أو الأشغال الشاقة المؤبدة أو الاعتقال المؤبد حولت العقوبة إلى الحبس سنة على الأقل. وإذا كان الفعل يؤلف إحدى الجنايات الأخرى كان الحبس من ستة أشهر إلى سنتين. وإذا كان الفعل جنحة فلا تتجاوز العقوبة الحبس ستة أشهر أو الغرامة خمسة وعشرين ديناراً.

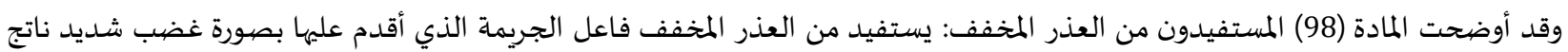
عن عمل غير محق وعلى جانب من الخطورة أتاه المجني عليه.

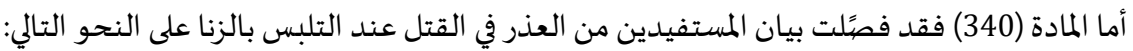
يستفيد من العذر المحل، من فاجأ زوجته أو إحدى محارمه حال التلبس بالزنا مع شخص آخر وأقدم على قتلهما أو جرحهما أو إيذائما كليهما أو إحداهما. يستفيد مرتكب القتل أو الجرح أو الإيذاء من العذر المخفف إذا فاجأ زوجها أو إحدى اصوله أو فروعاء أو أخواته مع آخر على فراش غير مشروع. وقد تم تعديل نص هذه المادة بالقانون رقم 8 لسنة 2011 بحيث أصبح نصيها بعد التعدئ التعديل على النحو التالي:

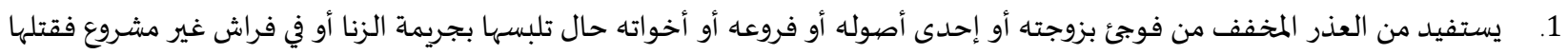

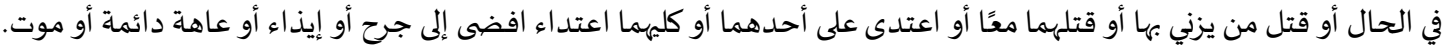

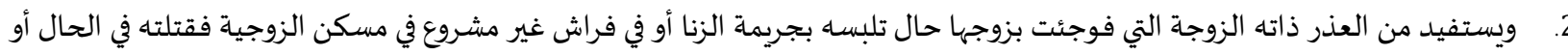
قتلت من يزني بها أو قتلتهما معًا أو اعتدت على أحدهما أو كليهما اعتداء أفضى إلى جرح أو إيذاء أو عاهة دائمة أو موته ولا يجوز استعمال حق الدفاع الشرعي بحق من يستفيد من هذا العذر. كما لا تطبق على من يستفيد من العذر المخفف أحكام الظروف المشددة.

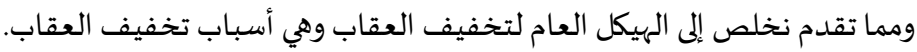

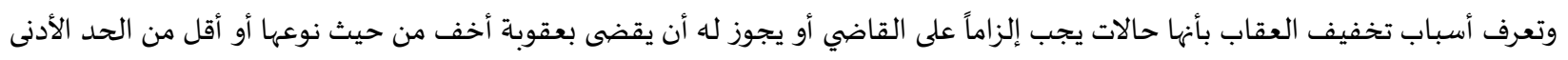
المقرر لعقوبة الجريمة أصلاً. وترتكن أسباب التخفيف بصورتيها إلى علة واحدة وهي رؤية الشارع أن العقوبة المقررة قد تكون (عند تطبيقها على بعض الحالات) غير ملائمة

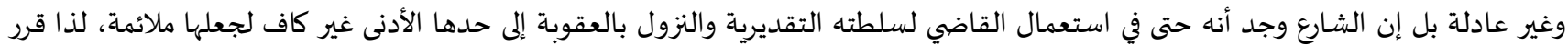

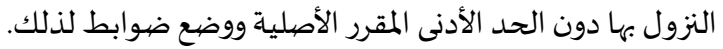
ويقصد المشرع بهذا المسلك تحقيق الملاءمة بين العقوبة وظروف حالات خاصة. (حسني، شرح قانون العقويات - القسم العام، 1982، صفحة

وتنقسم أسباب التخفيف إلى نوعين، أسباب تخفيف وجوبية ويطلق علها "الأعذار المخففة" وهي ما ينطوي تحت لوائها موضوع الدراسة على النحو الذى سنوضحه لاحقاً، وأسباب تخفيف جوازية ويطلق عليها "الظروف المخففة" وهي تخول القاضي في نطاق قواعد قانونية محددة الحكم

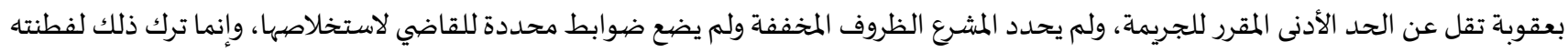

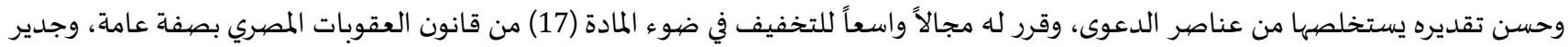
بالذكر أن نطاق الظروف المخففة ينحصر فقط في الجنايات دون الجنح والمخالفات وذلك لعدم جدواها فئاهي في الحالتين الأخيرتين.

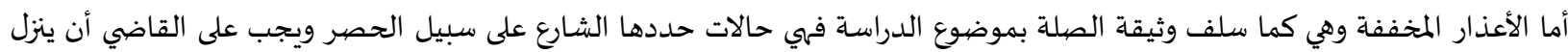

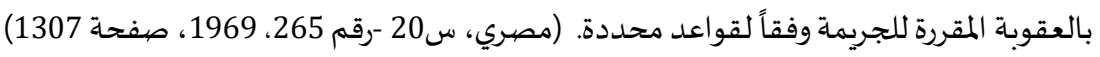


ويجد مبدأ الشرعية مكانه بالنسبة لحالات التخفيف الوجوبي بشكل عام فالمشرع هو الذي تولى تحديد الأعذار القانونية المخففة ومن ثم يوضح

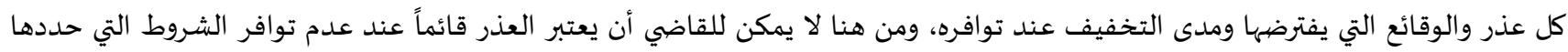

ومن ناحية أخرى لا يستطيع القاضي إنكار وجود العذر عند توافره، كما أنه ملزم بأن يشير في حكمها إلى العذر ويبين دلائل توافر شرطها. نوعا الأعذار المخففة: تنقسم الأعذار المخففة إلى نوعين عامة، وخاصة.

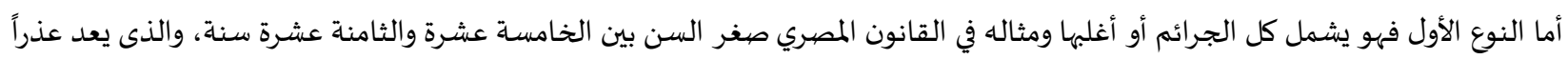
مخففاً لعقوبات الجنايات وفقاً للإطار المحدد قانوناً.

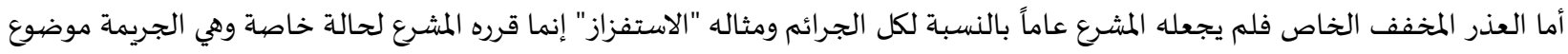

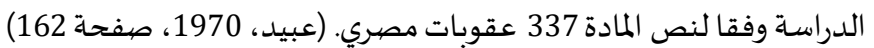

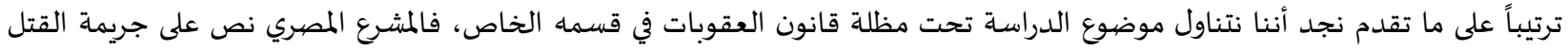

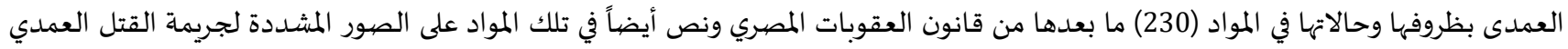

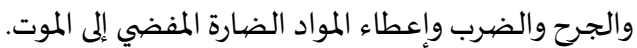
وقد نص الشـارع المصري على الجريمة موضوع الدراسة في المادة (237) عقوبات مصري على النحو الذى سنعرض لله في المبحث التالي.

المبحث الثاني: القتل العمدي في صورته المخففة قتل الزوج زوجته إذا فاجأها متلبسـة بالزنا

لا يعاقب المشرع المصري على ارتكاب جريمة القتل في جميع صورها بذات العقوبة المقررة لها بداءة في كلها المجرد عند اقتران السلوك الإجرامي بظرف التلبس بالزنا، بينما المشرع الفلسطيني كان يسير على نهج التخفيف تشريعاً وقضاء حتى أتي المشرع الفلسطيني بالقرارين بقانون في عامي

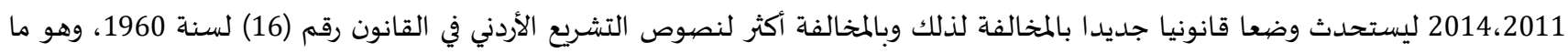
سنعرض له على النحو التالي:

المطلب الأول: نطاق التخفيف وسلطة القضياء عند التلبس بالزنا نص المشرع المصري على القتل العمدى في صورته المخففة في المادة 237 عقوبات حيث نص على "من فاجأ زوجته حال تلبسها بالزنا فقتلها في

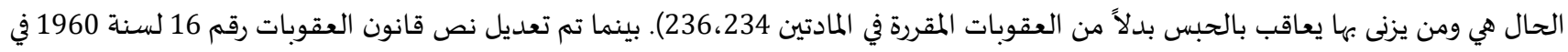

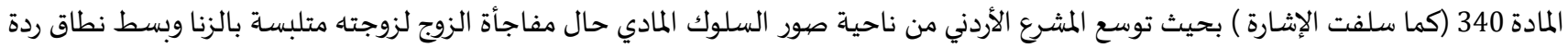

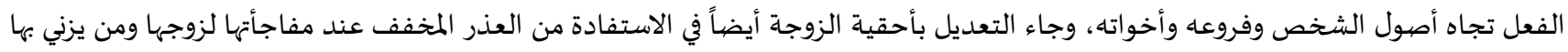

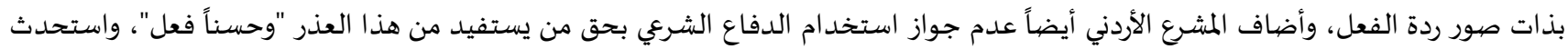
المشرع الأردني أيضاً عدم جواز تطبيق أحكام الظروف المشددة على من يستفيد من هذا العذر. وعلى صعيد آخر يجرى مسلك القضاء الفلسطيني (المطبق في قطاع غزة في ظل عدم وجود نص تشريعي مباشر لمعالجة تلك الحالة) على تطبيق

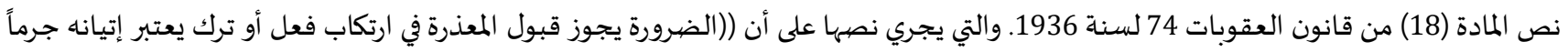

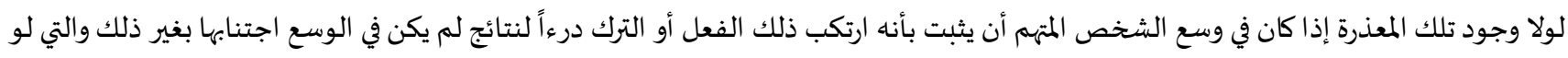

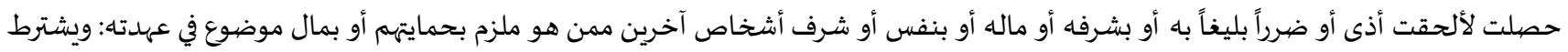

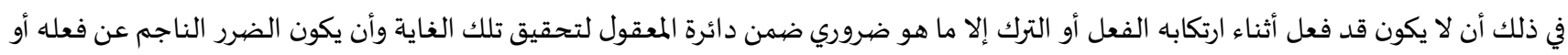
تركه متناسباً مع الضرر الذي تجنبها).

ويرى الباحث أن هذا التطبيق لحكم المادة المذكورة هو استخدام في غير محلاه حيث تعالج تلك المادة حالة الدفاع الشرعي. والقتل المقصود في الحالة المذكورة هو قتل مقترن بعذر قانوني، لذلك كان التخفيف وجوبياً في مسلك المشرع المصري والفلسطيني في الضفة الغربية (هدياً بمسلك المشرع الأردني)، بينما هو سلطة تقديرية للمحكمة في ظل القانون 74 لسنة 1936. وجرى بالقول أن نطاق التخفيف في هذه الحالة لا يقتصر فقط على القتل، وإنما يمتد كذلك إلى الجرح أو الضرب المبردي المفضي إلى الموت، ويتضح

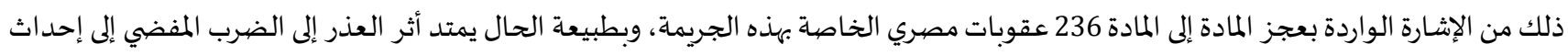

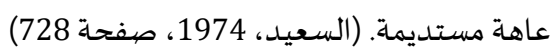

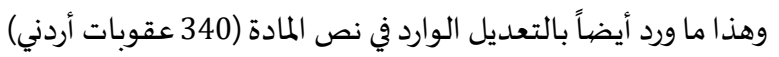

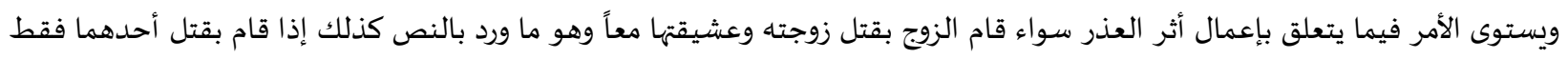

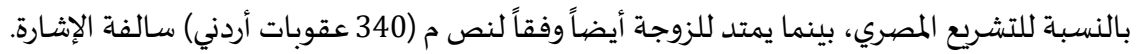




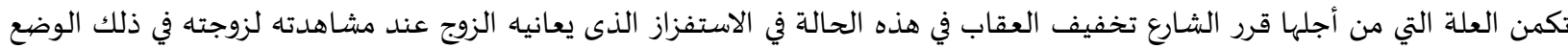

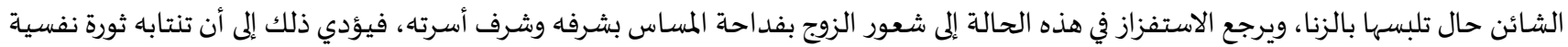

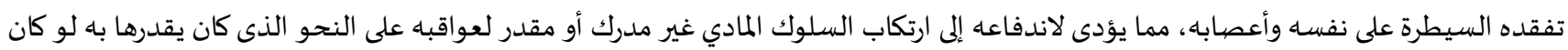
في حالته العادية. (رمضان، 1986، صفحة 281) • الطبيعة القانونية للقتل العمدي المخفف: القتل العمدي المخفف هو نوع من القتل العمدي خفف الشارع عقوبته، ويعنى ذلك بداءة أنه يشترط توافر كافة أركان القتل العمدي. (سرور، 1986، صفحة 555)

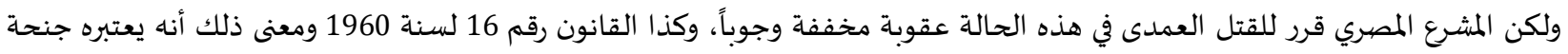

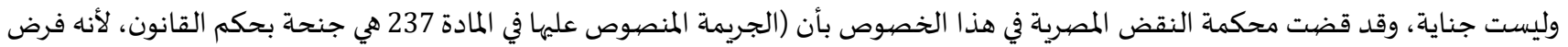

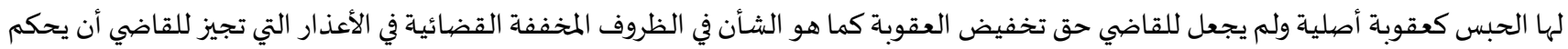

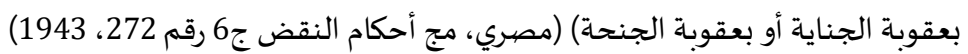

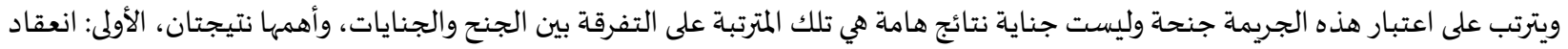

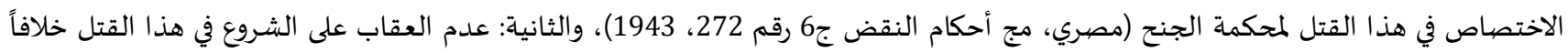

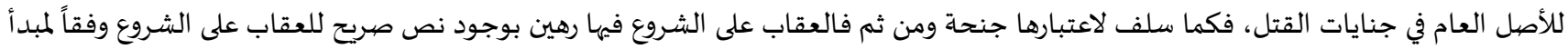

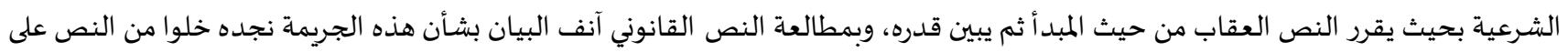
العقاب على الشروع في هذه الحالة.

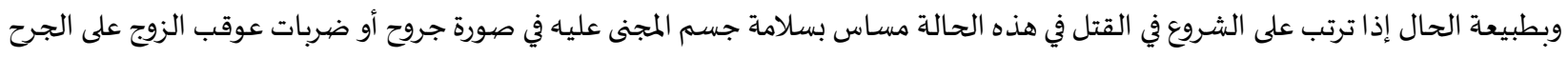
والضرب دون أن تجاوز عقوبته الحبس باعتباره عقوبة القتل. (حسني، شرح قانون العقوبات - القسم الخاص، 1986، صفحة المطلب الثاني: الشروط الموجبة للتخفيف

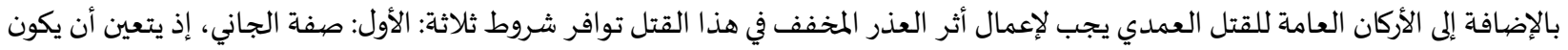

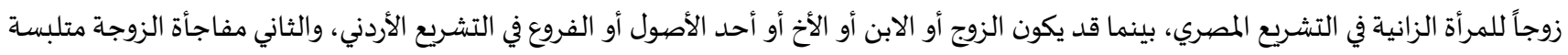

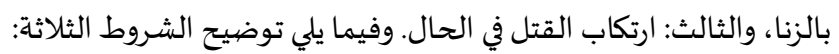
أولاً: صففة الجاني: وفقاً للتنظيم القانوني المصري لا يستفيد من تخفيف العقاب إلا الزوج فقط، فأقارب الزوجة أياً كانوا لا يستفيدون منه حتى ولو كانت صلتهم بها

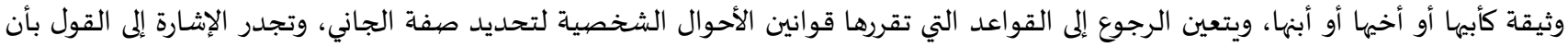

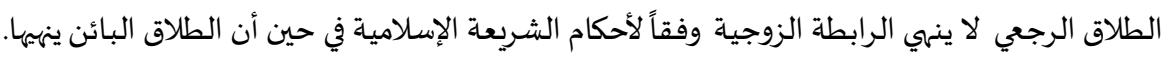

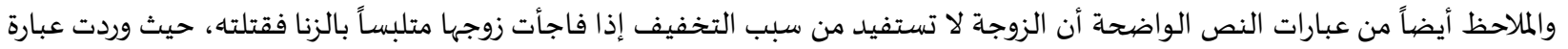

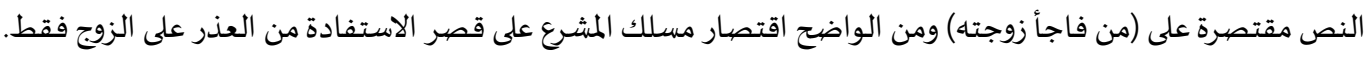

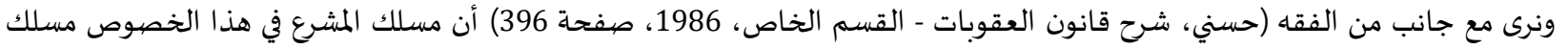

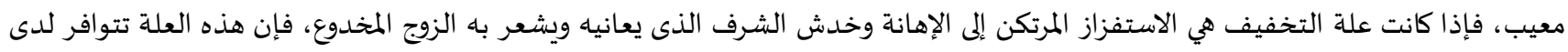

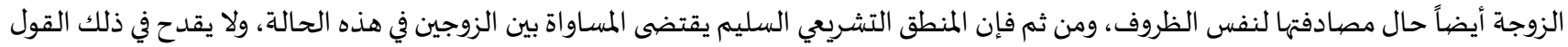

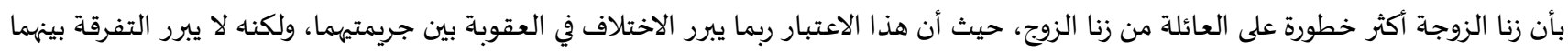

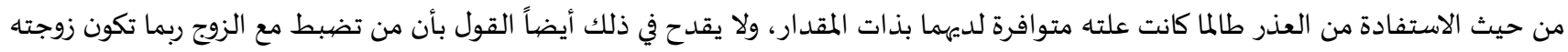

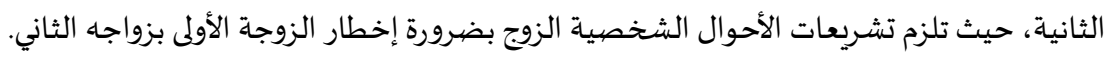

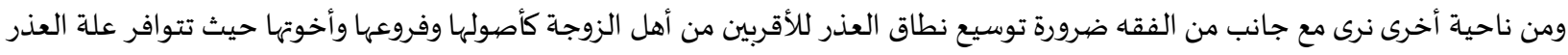

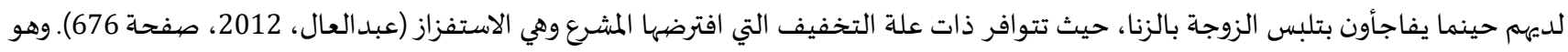

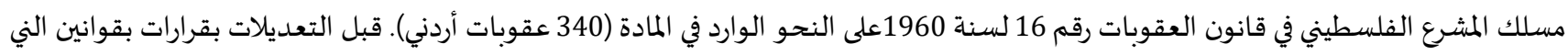
أدخلها المشرع الفلسطيني على نص تلك المادة وفقاً لما سيلي بيانه لاحق في هذه الدراسة. 
موقف المساهمين مع الزوج في قتل زوجته:

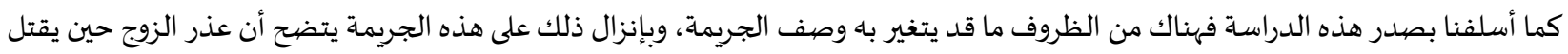

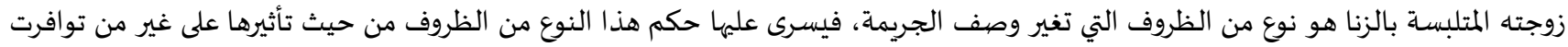

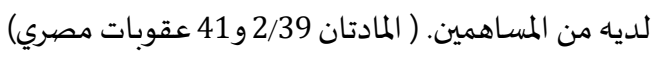

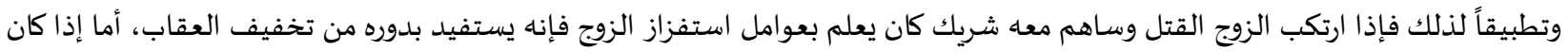

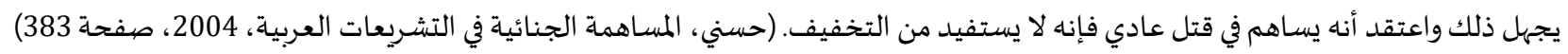

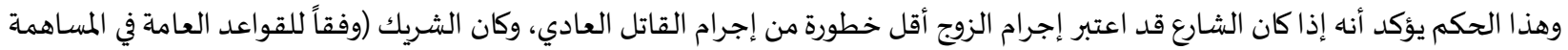

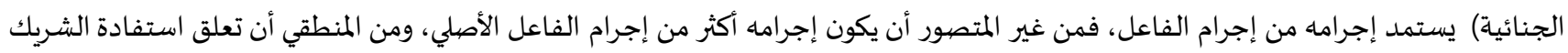

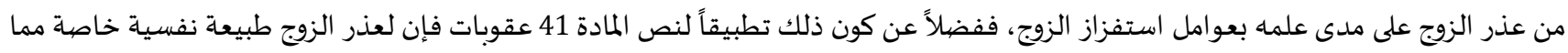

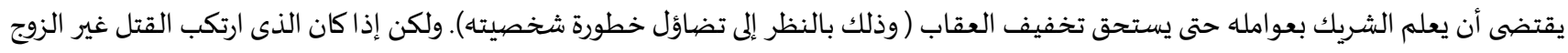

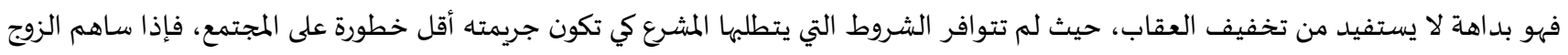

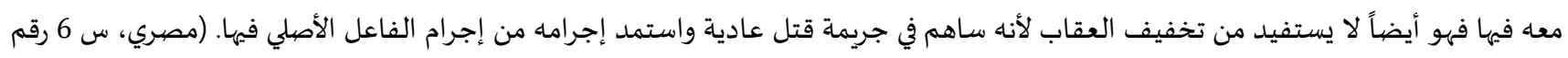

(1925، 296

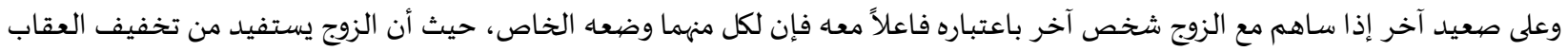

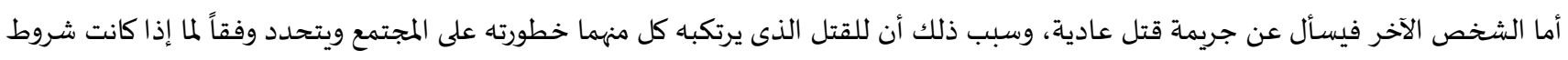

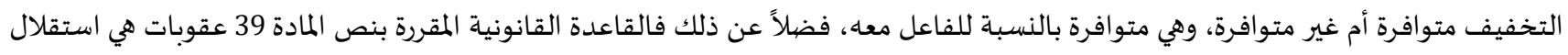
كل من الفاعلين من حيث الظروف التي تتوافر لأحدهم. ثانياً: مفاجأة الزوجة متلبسة بالزنا:

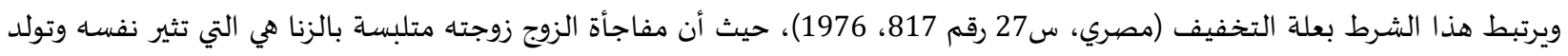

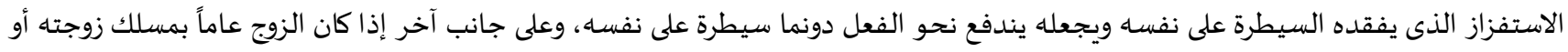

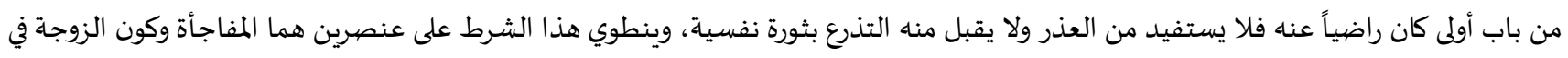
حالة تلبس بالزنا، وسنوضح ذلك فيمان يلي:

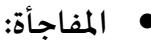

وهي اختلاف بين العقيدة والواقع أي بين ما كان يعتقده الزوج من سلوك زوجته المخلص له وبين ما استبان له عكس ذلك حينما شاهدها متلبسة

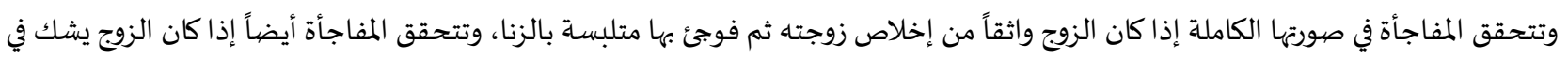

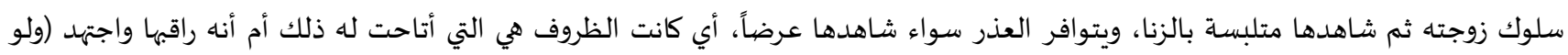

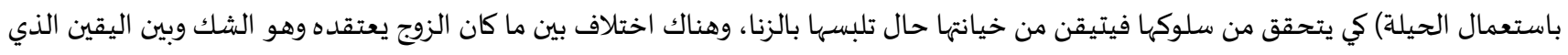

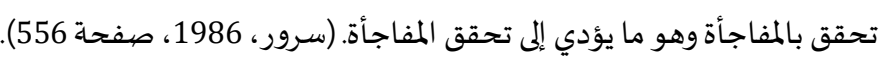

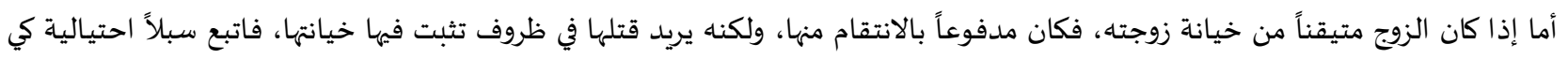

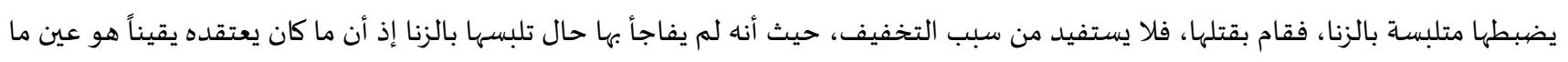

تحقق بالفعل.

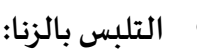

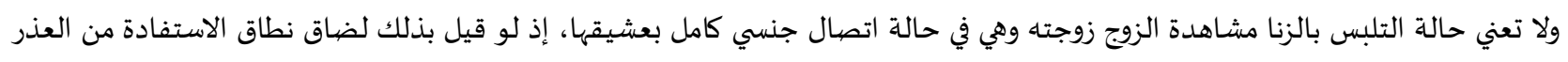

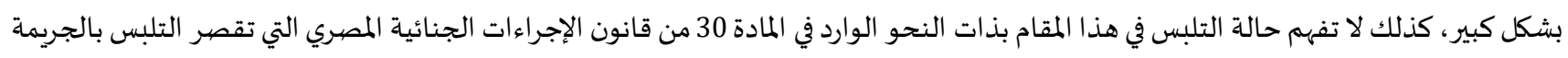

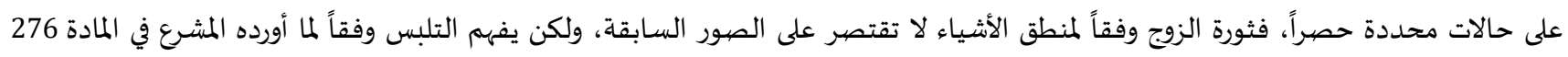

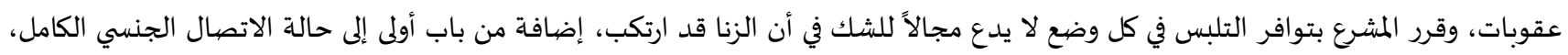

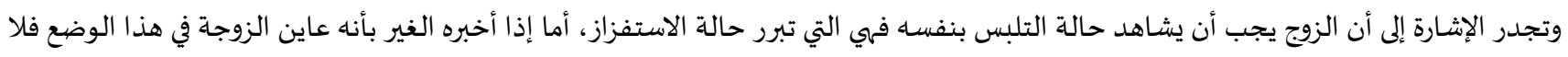

يتوافر العذر وفقاً لهذه الحالة الأخيرة. (المرصفاوي، 1987، صفحة اندان 214) 


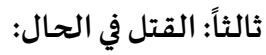

ويعني هذا الشرط التعاصر بين المفاجأة وما ينبعث عنها من استفزاز وبين ردة الفعل المتمثلة في ارتكاب القتل، ويتصل هذا الشرط اتصالاً وثيقاً

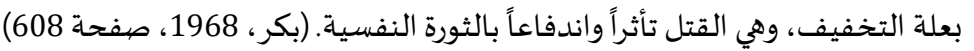

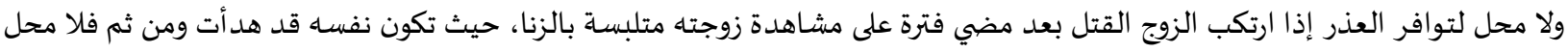

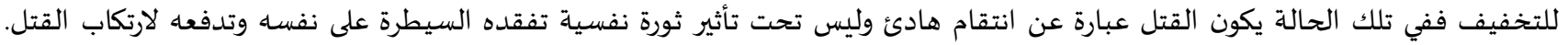

(مصطفى، 1974، صفحة 273)

وبالنظر إلى هذا الشرط يتبين أنه ذو طابع زمني مرجعها إلى تقدير الوقت الذي يفصل بين المفاجأة والفعل، وتقدير ذلك متروك لقاضي الموضوع.

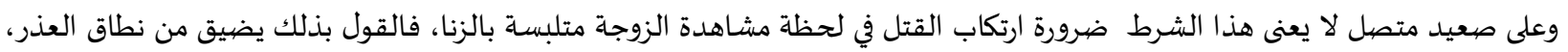

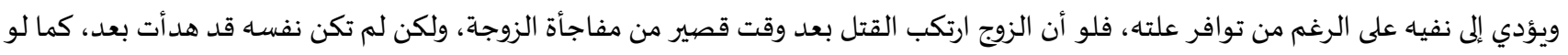

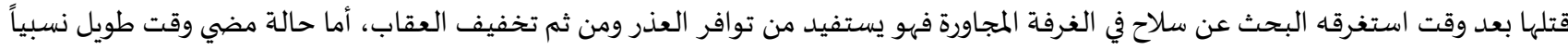

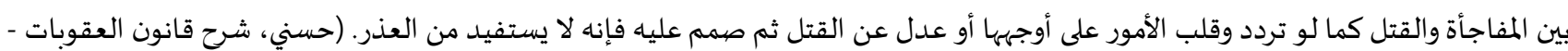

القسم الخاص، 1986، صفحة

\section{م العلاقة بين العذر القانوني وسبق الإصرار:}

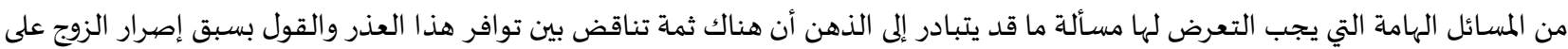

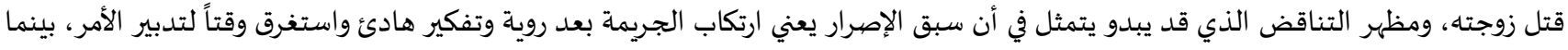

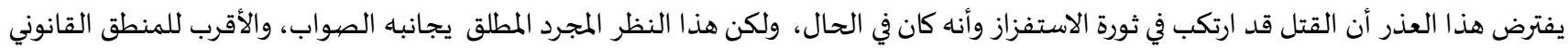

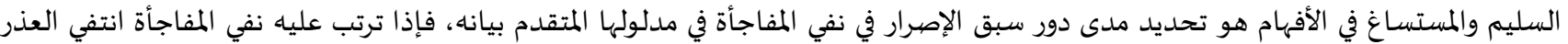

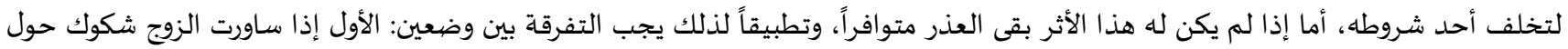

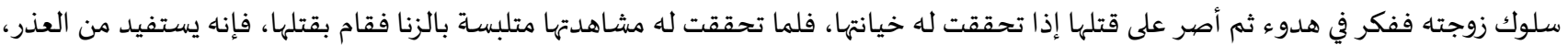

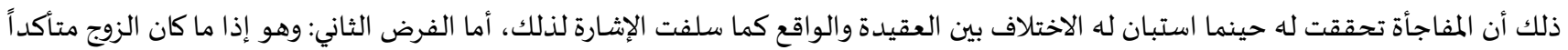

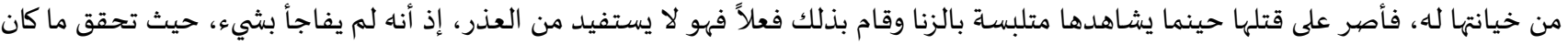

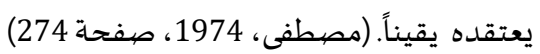
عقوبة القتل المقترن بالعذرفي القانون المصري:

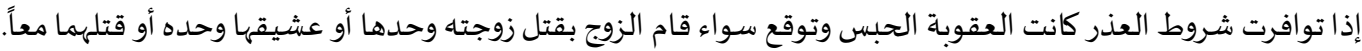

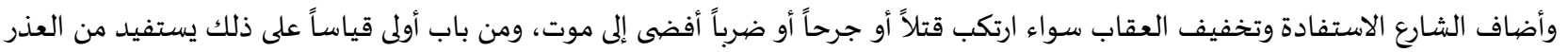

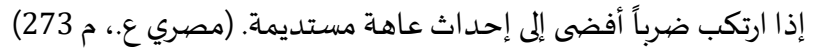

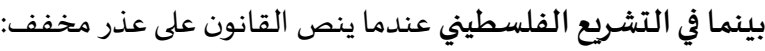

1.

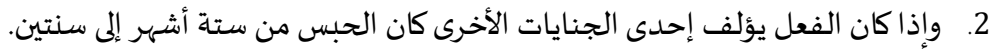

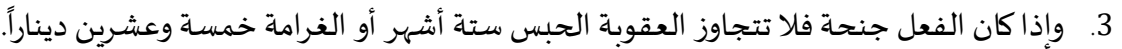

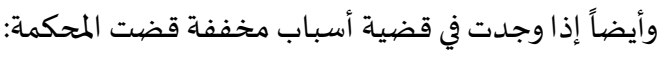

1. بدلاً من الإعدام بالأشغال الشاقة المؤبدة أو بالأشغال الشاقة المؤقتة من عشر سنين إلى عشرين سنة.

2. بدلاً من الأشغال الشاقة المؤبدة بالأشغال الشاقة المؤقتاة من خمس سنوات إلى خمس عشرة سنة وبدالاً من الاعتقال المؤبد بالاعتقال المؤقت مدة

لا تقل عن خمس سنوات.

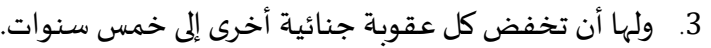

4. ولها أيضاً ما خلا حالة التكرار، أن تخفض أية عقوبة لا يتجاوز حدها الأدنى ثلاث سنوات إلى الحبس سنة على الأقل.

المطلب الثالث: مسلك المشرع الفلسطيني للتعديل

إزاء ردود الفعل المجتمعية المختلفة لبعض الجرائم التي ارتكبت بدافع الشرف ثم تبين براءة الضحية من تلويث الشرف عند تشريح جثتها فقد

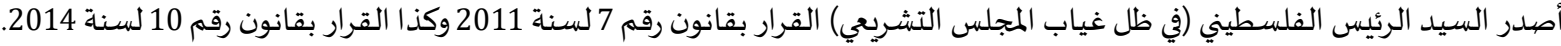

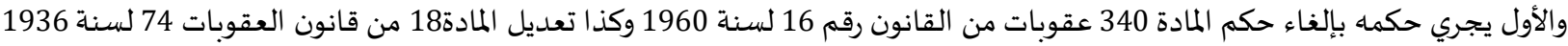

مؤكدا على إلغاء ما يسمى بدافع الشرف كعذر للقتل، ومن ثم فهي جريمة قتل عادية بما يصاحها من ظروف، وجاء الماء القرار بقانون الثاني ليلغي تماماً 
نص المادة 98 من قانون العقوبات 16 لسنة 1960 سالفة البيان فيما يخص "دافع الشرف" وقد ورد القراران على النحو التالي :(( قرار بقانون رقم (7) (2011)

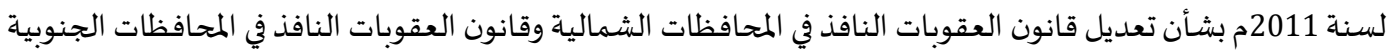
رئيس دولة فلسطين رئيس اللجنة التنفيذية لمنظمة التحرير الفلسطينية رئيس السلطة الوطنية الفلسطينية بعد الاطلاع على القانون الأسـاسي

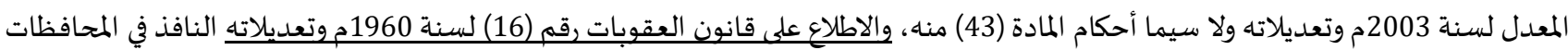
الشمالية، والاطلاع على قانون العقوبات رقم (74) لسنة 1936م وتعديلاته النافذ في المحافظات الجنوبية، والاطلاع على قرار مجلس الوزراء رقم

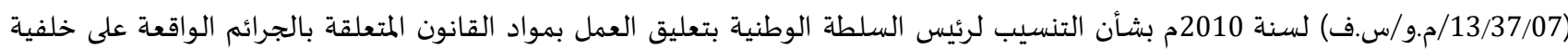

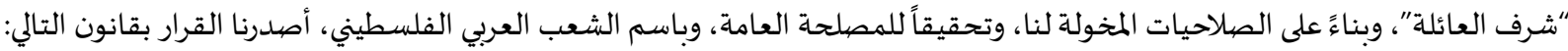
مادة (1): بموجب أحكام هذا القرار بقانون يلغي نص المادة (340) من الفصل الأول من الباب الثامن من قانون العقوبات رقم (16) لسنة 1960م النافذ في المحافظات الشمالية. مادة (2): يعدّل نص المادة رقم (18) من قانون العقوبات رقم (74) لسنة 1936م النافذ في المحافظات الجنوبية وذلك بإضافة عبارة (ولا يشمل ذلك جرائم قتل النساء على خلفية “شرف العائلة") في آخر المادة.

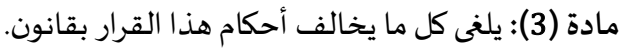

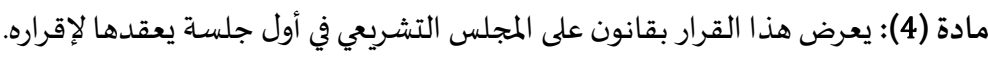
مادة (5): على الجهات المختصة كافة، كل فيما يخصاه، تنفيذ أحكام هذا القرار بقانون، ويعمل باه من تاريخ نشره في الجريدة الرسمية.

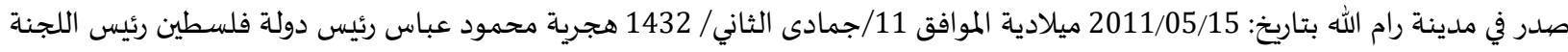
التنفيذية لمنظمة التحرير الفلسطينية رئيس السلطة الوطنية الفلسطينية بينما ورد القرار بقانون 10 لسنة 2014 على النحو التالي: قرار بقانون رقم (10) لسنة 2014م بشأن تعديل قانون العقوبات رقيه (16) لسنة 1960م.

رئيس دولة فلسطين رئيس اللجنة التنفيذية لمنظمة التحرير الفلسطينية استناداً لأحكام القانون الأساسي المعدل لسنة 2003م وتعديلاته، ولا سيما المادة (43) مناء، وبعد الاطلاع على قانون العقوبات رقهم (16) لسنة 1960موتعدئيلاته، وبناءً على الصهاحيات المخولة لنا، وتحقيقاً للمصلحة العامة، وباسم الشعب العربي الفلسطيني، أصدرنا القرار بقانون التالي:

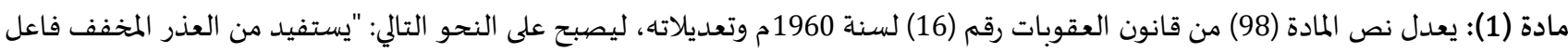
الجريمة الذي أقدم عليها بثورة غضب شديد ناتج عن عمل غير محق وعلى جانب من الخطورة أتاه المجني عليه، ولا يستفيد فاعل الجريمة من هذا

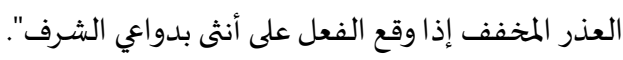
مادة (2): يلنى كل ما يخالف أحكام هذا القرار بقانون.

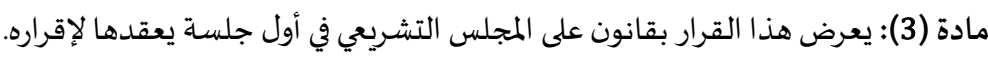
مادة (4): على الجهات المختصة كافة، كل فيما يخصيه تنفيذ أحكام هذا القرار بقانون، ويعمل بـان باه من تاريخ نشره في الجريدة الرسمية.

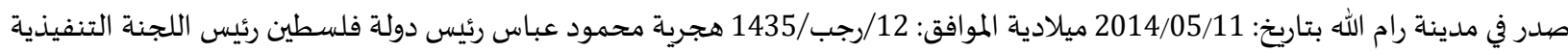

المنظمة التحرير الفلسطينية)( وبتدقيق النظر في تاريخي صدور القرارين بقانون الصادرين عن رئيس السلطة الفلسطينية يتبين أن الأول صددر بتاريخ 15-5-2011 والثاني بتاريخ

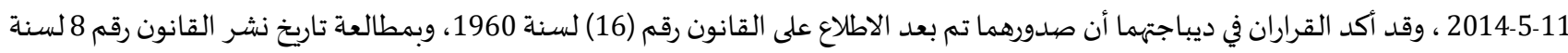
2011 الصادر بتعديل بعض أحكام قانون العقوبات رقم (16) لسنة 1960 ومنها المادة (340) على النحو سالف البيان يتبين أنه قد نُشر بالجريدة

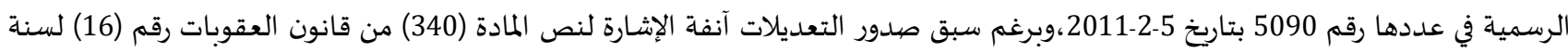
1960 إلا أن القرارين بقانون سالفي البيان قد أوردا الأحكام متقدمة البيان فيهما والتي تقطع بتوجه المشرع الفلسطيني نحو إلغاء كل عذر أو تخفيف الفها

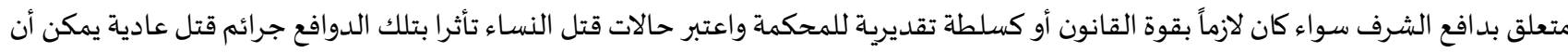
تقترن بالظروف المشددة إن اقترنت بها.

الخاتمة: يعتبر المشرع المصري القتل بدافع الشرف عذراً قانونياً مخففاً، ويقصر الاستفادة من العذر على الزوج وحدة دون الزوجة وأيضاً على الزوج دون

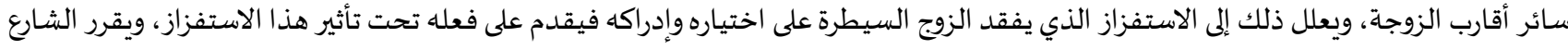

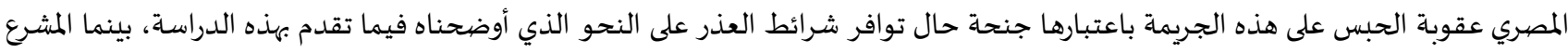
الفلسطيني وفقاً لقانون العقوبات رقم 74 لسنة 1936كان المرتكز للقضاء الفلسطيني هو نص المادة 18 سالفة البيان وفي القانون 16 لسنة 1960 
كانت المواد 98 والمادة 340 ولكن بصدور القرارين بقانون رقم 7 لسنة 2011 و10 لسنة 2014 أصبحت هذه الحالة جريمة قتل عادية دون آية أعذار،

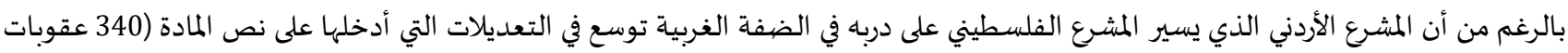
أردني) من حيث صور السلوك الإجرامي والنطاق الشخصي للاستفادة من هذا العذر وذلك بما أورده من تعديلات بالقانون رقم 8 لسنة وفي الختام خلصت هذه الدراسـة إلى مجموعاة من النتائج والتوصيات على النحو التالي:

قصر المشرع المصري حق الاستفادة من العذر على الزوج فقط وضد الزوجة وحدها دون باقي أخواته أو أصوله أو فروعه. توسع المشرع الأردني بموجب تعديلاته لقانون العقوبات 16 لسنة 1960من حيث منح الرجل الحق في الاستفادة من العذر ضد أخواته أو إحدى أصوله أو إحدى فروعـه

منح المشرع الأردني للزوجة حق الاستفادة من العذر حال مفاجأتها للزوج متلبساً بارتكاب الزنا. عطّل المشرع الفلسطيني كل أحكام التخفيف الجوازي، والوجوبي المتعلقة بقتل النساء على خلفية الشرف أو داعي الشرف. ألغى المشرع الفلسطيني حكم نص المادتين 98،340عقوبات في حال ارتباطهما بقتل النساء على خلفية الشرف. تنوعت المعالجة التشريعية الفلسطينية لموضوع قتل النسـاء بدافع الشرف بين قانون العقوبات رقم 74 لسنة 1936 وقانون العقوبات الأردني 16

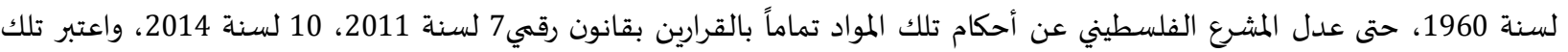

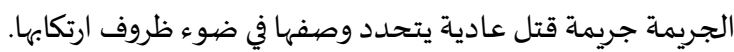

ثانياً: التوصيات:

في ختام هذه الدراسة نوصى ببعض التوصيات على النحو التالي: توسيع نطاق من يشملهم العذر ويستفيدون من التخفيف بحيث يشمل أصهول الزوجة وفروعها وأشقائها في التشريع المصري. تمكين الزوجة من الاستفادة من التخفيف حال مشاهدتها لزوجها حال تلبساه بالزنا في التشريع المصري. المساواة في العقاب والأركان بين زنا الزوج وزنا الزوجة.

تقرير الجريمة متكاملة في حق الزوج إذا ارتكبها في أي مكان ولا تقتصر على منزل الزوجية فقط. إلغاء عجز المادة 273 عقوبات مصري فيما يتعلق بعدم سماع دعوى الزوج (الذي يثبت ارتكابه للزنا بمنزل الزوجية وفقاً لنص المادة 277 عقوبات مصري) على زوجته التي يثبت ارتكابها لجريمة الزنا. أن يعيد المشرع الفلسطيني النظر في معالجة هذه الجريمة بقانون موحد يطبق على الكل الفلسطيني مستلهماً أحكامه من مسلك المشرعين المصري والأردني.

1. الأشقر، أحمد (2004). جرائم قتل النساء بداعي الشُف في فلسطين. تم الاسترداد من مكتبة رام الله العامة: 2. بكر، عبد المهيمن (1968). القسم الخاص في قانون العقوبات. القاهرة: دار النهضة العربية. 3. حسني، محمود نجيب (1982). شسح قانون العقويات - القسمى العام. القاهرة. 4. حسني، محمود نجيب. (1986). شرح قانون العقوبات - القسم الخاص. القاهرة: دار الهضية العربية. 5. ر رمضان، عمر السعيد (1986). شرح قانون العقوبات - القسمى الخاص. القاهرة: دار الهضية العربية. 6. سرور، أحمد فتحي (1986). شـح قانون العقوبات - القسم الخاص. القاهرة: دار النهضة العربية. 7. 8. عازر، عادل (1966). النظرية العامة في ظروف الجبيمة. القاهرة: المطبعة العلمية. 9 9. عبدالعال، أيمن نصر (2012). مظاهر الإخلال بالمساواة في الإجراءات الجنائية. القاهرة: المركز القومي للإصدارات العات القانونية.

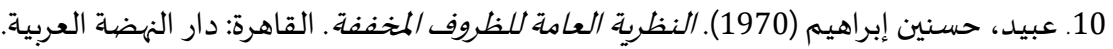
11. عقوبات مصري. (م 273).

12. محمود نجيب حسني. (2004). المسباهمة الجنائية في التشريعات العربية. القاهرة: دار النهضية العربية. 13. المرصفاوي، حسن صادق (1987). شرح قانون العقوبات - القسم الخاص. الاسكندرية: منشأة المعارف بالاسكندرية. 14. مصطفى، محمود محمود (1974). شرح قانون العقوبات - القسم العام. القاهرة: دار النهضية العربية. 
15. نقض جنائي مصري. (3 11، 1925). س 6 رقم 296. القاهرة.

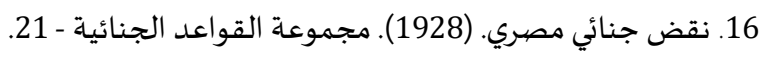

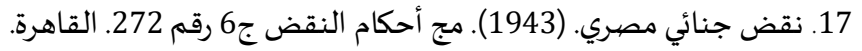

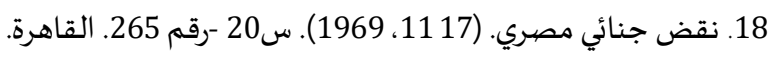

19. نقض جنائي مصري. (19761،1191). س27 رقم 817. القاهرة. 


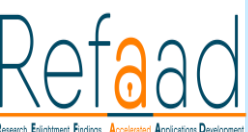

www.refaad.com
المجلة الدولية للدراسات القانونية والفقهية المقارنة

International Journal of Legal and Comparative Jurisprudence Studies (LCJS)

Journal Homepage: https://www.refaad.com/views/LCJS/Home.aspx ISSN: 2708-6607(Online) 2708-6593(Print)

\title{
Honor killing- comparative analytical study between Egyptian and Palestinian legislation
}

\author{
Ayman Nasr Abd Elaal \\ Assistant Professor of Criminal Law, Dean of the College of Law and Judicial Practice, University of Palestine \\ dr.aymannasr66@gmail.com
}

Received: 17/8/2021 Revised: 3/10/2021 Accepted: 20/10/2021 DOI: https://doi.org/10.31559/LCJS2021.2.3.1

Abstract: Life is a great blessing granted by God Almighty to man and imposing its protection as established by the heavenly laws to protect the human soul from any aggression. The previous year of protection and among those cases is the case of provocation based on surprise when shocked, from the demolition of the thick pact between the spouses, as a waste of the husband's dignity or the woman's origins or her closest descendants in some legislation, in addition to the husband. Hence, this study came to show the legislative treatment in the Palestinian and Egyptian legislations as a guide to the behavior of the Jordanian legislator whose behavior is followed by the Palestinian legislator. One of its origins or branches is the exact opposite of the Jordanian legislator, just as the Palestinian legislator abolished this excuse legally and judicially.

Keywords: murder; honor motive; premeditated; mitigating excuse; adultery crime.

\section{References:}

1. Alashqr, Ahmd (2004). Jra'm Qtl Alnsa' Bda'y Alshrf Fy Flstyn. Tm Alastrdad Mn Mktbt Ram Allh Al'amh: http://ramallah.noursoft.com/records/index/1/732236

2. Bkr, 'bdalmhymn (1968). Alqsm Alkhas Fy Qanwn Al'qwbat. Alqahrh: Dar Alnhdh Al'rbyh.

3. Hsny, Mhmwd Njyb (1982). Shrh Qanwn Al'qwyat - Alqsm Al'am. Alqahrh.

4. Hsny, Mhmwd Njyb. (1986). Shrh Qanwn Al'qwbat - Alqsm Alkhas. Alqahrh: Dar Alnhdh Al'rbyh.

5. $\quad$ Rmdan, 'mr Als'yd (1986). Shrh Qanwn Al'eqwbat - Alqsm Alkhas. Alqahrh: Dar Alnhdh Al'rbyh.

6. Srwr, Ahmd Fthy (1986). Shrh Qanwn Al'qwbat - Alqsm Alkhas. Alqahrh: Dar Alnhdh Al'rbyh.

7. Als'yd, Mstfa Als'yd (1974). Alqanwn Aljna'y. Alqahrh: Dar Alnhdh Al'rbyh.

8. 'azr, 'adl (1966). Alnzryh Al'amh Fy Zrwf Aljrymh. Alqahrh: Almtb'h Al'lmyh.

9. 'bdal'al, Aymn Nsr (2012). Mzahr Alekhlal Balmsawah Fy Alejra'at Aljna'yh. Alqahrh: Almrkz Alqwmy Llesdarat Alqanwnyh.

10. 'byd, Hsnyn Ebrahym (1970). Alnzryh Al'amh Llzrwf Almkhffh. Alqahrh: Dar Alnhdh Al'rbyh.

11. 'qwbat Msry. (M 273).

12. Mhmwd Njyb Hsny. (2004). Almsahmh Aljna'yh Fy Altshry'at Al'rbyh. Alqahrh: Dar Alnhdh Al'rbyh.

13. Almrsfawy, Hsn Sadq (1987). Shrh Qanwn Al'qwbat - Alqsm Alkhas. Alaskndryh: Mnshat Alm'arf Balaskndryh.

14. Mstfa, Mhmwd Mhmwd (1974). Shrh Qanwn Al'qwbat - Alqsm Al'am. Alqahrh: Dar Alnhdh Al'rbyh.

15. Nqd Jna'y Msry. (3 11, 1925). S 6 Rqm 296. Alqahrh.

16. Nqd Jna'y Msry. (1928). Mjmw'eh Alqwa'd Aljna'yh - 21.

17. Nqd Jna'y Msry. (1943). Mj Ahkam Alnqd J6 Rqm 272. Alqahrh.

18. Nqd Jna'y Msry. (17 11, 1969). S20 -Rqm 265. Alqahrh.

19. Nqd Jna'y Msry. (1 11,1976). S27 Rqm 817. Alqahrh. 